\title{
OPERATOR ROLE DEFINITION: AN INITIAL STEP IN \\ THE HUMAN FACTORS ENGINEERING DESIGN OF \\ THE ADVANCED NEUTRON SOURCE (ANS)
}

\author{
H. E. Knee \\ P. F. Spelt
}

M. M. Houser

W. E. Hill

Oak Ridge National Laboratory

P.O. Box 2009

RECErver

MAY 06 S

Oak Ridge, Tennessee 37831-8218

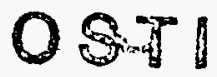

To be presented at the

38th Annual Meeting of the

Human Factors and Ergonomics Society

Nashville, Tennessee

October 24-28, 1994

\footnotetext{
"The submitted manuscript has been authored by a contractor of the U.S. Government under contract $D E-A C 05-840 R 21400$. Accordinghy, the U.S. Government retains a nanexclusive, royalty-free license to publish or reproduce the published form of this contribution, or allow others to do so, for U.S. Government purposes"
}

Research sponsored by the Office of Energy Research, U.S. Department of Energy, under contract DE-AC05-84OR21400 with Martin Marietta Energy Systems, Inc.

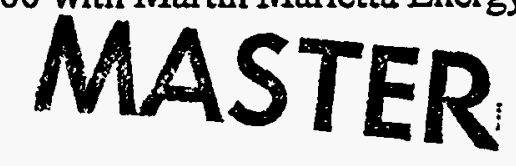




\title{
OPERATOR ROLE DEFINITION: AN INITIAL STEP IN THE HUMAN FACTORS ENGINEERING DESIGN OF THE ADVANCED NEUTRON SOURCE (ANS)
}

\author{
H. E. Knee \\ P. F. Spelt \\ M. M. Houser \\ W. E. Hill \\ Oak Ridge National Laboratory \\ Oak Ridge, TN
}

\begin{abstract}
The Advanced Neutron Source (ANS) is a new basic and applied research facility sponsored by the U.S. Department of Energy that is proposed for construction. It will provide neutron beams for measurements and experiments in the fields of materials science and engineering, biology, chemistry, materials analysis, and nuclear science. The facility will provide a useful neutron beam flux that is at least five times more than is available at the world's best existing facilities. It will also provide world-class facilities for isotopes production, materials irradiation testing, materials analysis, and the production of positrons. ANS will be unique in the United States in the extent to which human factors engineering (HFE) principles will be included in its design and construction. Initial HFE accomplishments include the development of a functional analysis, an operating philosophy, and a program plan. In fiscal year 1994, HFE activities are focusing on the role of the ANS control room reactor operator (RO). An operatorcentered control room model was used in conjunction with information gathered from existing ANS system design descriptions and other literature to define RO responsibilities. From this list, a survey instrument was developed and administered to ANS design engineers, operations management personnel at Oak Ridge National Laboratory's High Flux Isotope Reactor (HFIR), and HFIR ROs to detail the nature of the RO position. Initial results indicated that the RO should function as a high-level system supervisor with considerable monitoring, verification, and communication responsibilities. The relatively high level of control automation has resulted in a reshaping of the RO's traditional safety and investment protection roles.
\end{abstract}

\section{BACKGROUND}

\section{The Advanced Neutron Source}

The Advanced Neutron Source (ANS) will be a new basic and applied research facility based on a 330 MW, steady-state research reactor that will provide neutron beams for measurements in the fields of materials science and engineering, biology, chemistry, materials analysis, and nuclear science. The useful neutron flux for beam experiments will be at least five times more than is available at the world's best existing facilities. ANS will also provide irradiation capabilities to produce radioisotopes for applications in medicine, research, and industry. Materials irradiation facilities will match or exceed the capabilities of the Oak Ridge National Laboratory's (ORNL's) existing High Flux
Isotope Reactor (HFIR). The ANS reactor will be heavy-water cooled, moderated, and reflected and will include cooling systems with passive safety features that are conceptually similar to those planned for advanced. light water reactors generating commercial power. The ANS design will include relatively high levels of automation comparable to those in other systems with advanced controls. It will also be unique in the United States in the extent to which human factors engineering (HFE) principles will be included in its design and construction.

In addition to being a reactor facility, ANS will also contain some rather complex ancillary processes. A cryogenic moderator, which will be used to slow down neutrons for particular experiments, and a plant to remove the tritium from the heavy water (i.e., a detritiation facility) are also included. 


\section{Purpose of the Study}

The ANS team is committed to a design that meets the requirements of both the U.S. Department of Energy (DOE) and the U.S. Nuclear Regulatory Commission (NRC), such as Chapter 18 of NUREG0800 (Safety Analysis Report for Nuclear Power Plants Human Factors Engineering). Furthermore, in light of the facts that the accidents at Three-Mile Island (TMI) and Chernobyl involved human error, and ANS will be one of the first reactors designed and built in the United States since the TMI accident, emphasis on HFE principles during design is highly desirable.

During the conceptual design phase of ANS (fiscal year 1992), human factors efforts were initiated. These efforts included the development of a detailed HFE program plan (HFEPP) that addressed necessary human factors activities throughout the design and construction phases. This plan included the definition of personnel roles, allocation of functions, task analyses, and nine other HFE activities. In addition, an ANS operating philosophy (Houser, 1993) was developed based on 24 key operational issues as identified by the ANS project design team. In fiscal year 1993, efforts were focused on a functional analysis for ANS. This analysis yielded ten primary ANS functions, including neutron production, refueling operations, and maintenance. From this set, refueling and maintenance were selected for more detailed task analysis. In order effectively to complete these task analyses, however, it was necessary to define the roles of reactor operators (ROs): this paper will focus on defining that task.

The results of this study will support the activities described in the HFEPP. Specifically, the study will support decisions related to allocations of functions and automation, the design of the control room complex, the human-system interface, and the ANS procedures and training.

\section{Basis for the Approach Taken in this Study}

This study is based on previous research on the role of the RO (Spelt, 1993). That 1993 study focused on the determination of the consensus that exists with respect to the role of the RO in various types of nuclear power generating stations in North America. The results of this determination provide a framework for ascertaining the similarities and differences among the RO definitions for the various existing and planned reactors.

The approach for the present study involved three primary elements:
1. a taxonomy for describing the role of the RO, which involved passive monitoring, cognition, physical manipulation/control, training requirements, and communication;

2. identification of specific RO job characteristics, including allocations of responsibility and control, determination of communication patterns, and coordination and interdependencies within teams; and

3. an operator-centered control rcom model (Fig. 1) that accounted for all influences in the control room environment.

Taken in concert, these three elements provided a framework for the development of a structured interview.

\section{DESCRIPTION OF THE APPROACH}

Initial efforts were focused only on the RO position during normal operation. (Other positions [such as the senior reactor operator, auxiliary operator, shift supervisor, and shift technical advisor] and off-normal operations will be addressed in later studies.) In addition, the study only addressed four technical areas (1) reactor operations, (2) refueling operations, (3) maintenance, and (4) research operations. Special consideration was also given to the RO's interactions with cryogenic operations, detritiation operations, and research support personnel.

In preparation for the development of the questionnaires for the interviews, the ANS human factors team reviewed existing ANS system design descriptions and other literature and met with selected ANS subject matter experts. The team engaged in several internal iterations that involved the development of preliminary lists of responsibilities, communication interfaces, and task activities. This information was subsequently distilled into the final questionnaires.

\section{TOPICS COVERED IN THE INTERVIEWS}

A questionnaire was developed for each of the four technical areas. Although the content and focus of the questionnaires were different, the emphasis of this study allowed the questionnaires to have a similar format and structure. The questionnaire for neutron production consisted of 33 open-ended questions in the following areas: (1) general (e.g., responsibilities and automation issues), (2) safe and reliable operation (e.g., technical specification compliance, monitoring strategies, and the use of and quality of procedures), (3) communication (intershift and intrashift), (4) maintenance and miscellaneous support, (5) hazard control [e.g., OSHA 


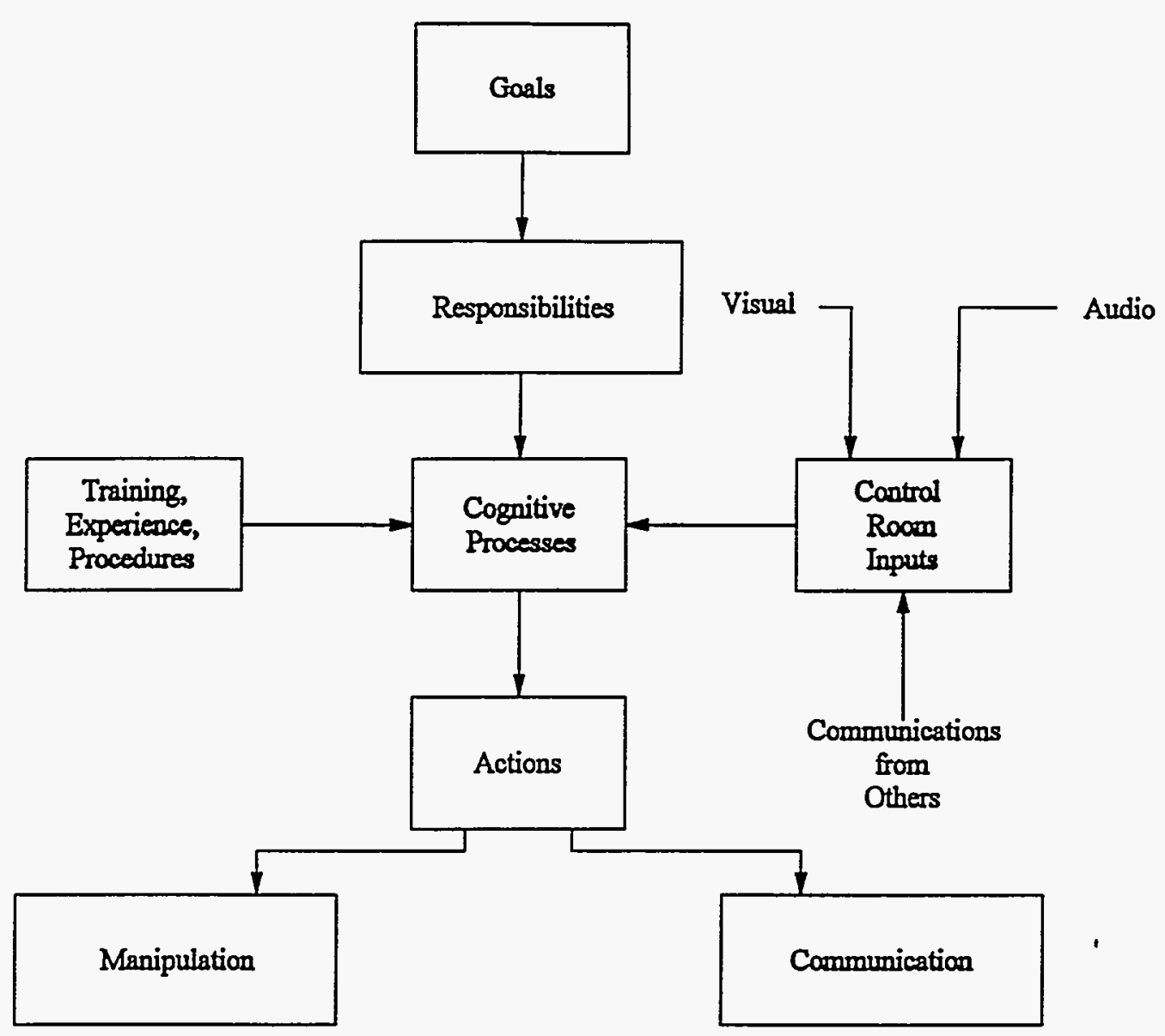

Figure 1. Operator-Centered Control Room Model

(Occupational Safety and Health Administration) compliance and contamination control], (6) special resource monitoring, and ( 7 ) certification requirements (training).

\section{THE INTERVIEWS AND SUBSEQUENT ANALYSES}

Each of the interviews was conducted over 2 hours, and the open-ended questions encouraged discussion. Responses and comments were recorded manually. On a number of occasions, the participants engaged in discussions among themselves on topic areas that had not been fully resolved in the design (e.g., the nature of the relationship between the RO and automated systems). Such discussions were welcomed because they provided valuable insights; however, the ANS human factors team was careful not to allow such discussions to dominate the interview period.

Following the interviews, the notes were integrated into a single document. The team then reviewed the integrated document for accuracy, resolved inconsistencies, and formulated a consensus on the role of the RO for each of the technical areas. In a few instances, the interviewees were recontacted for clarification and amplification of points made during the interviews.

\section{DESCRIPTION OF THE GROUPS INTERVIEWED}

The groups interviewed included representatives from the ANS design team and HFIR operators and operations management. Industrial and other government facilities are targeted for further information-gathering. Interviewees from the ANS design team were engineers involved in the design of specific reactor systems. In particular, design engineers in the following areas were contacted: instrumentation and controls, detritiation, cryogenics, cooling systems, core components, refueling, and irradiation and beam facilities. 
Those interviewed from HFIR operations management were personnel with engineering, operations, and training backgrounds. Some had operations experience at other reactors. The interviewees primarily had experience with control room technologies from the 1960s and 1970s. Their recent experiences with the modernization efforts at HFIR provided insight regarding the advantages and disadvantages associated with newer instrumentation, control and interface technologies, and strategies.

The HFIR operators interviewed were a shift crew of HFIR's certified operations staff. Many had nuclear military backgrounds but gained their primary RO experience at HFIR.

The representatives for industry and other government facilities to be contacted included personnel in the areas of nuclear power, detritiation, cryogenics, and other power-related processes. The facilities that have dealt with advanced controls were especially targeted for contact.

\section{HUMAN FACTORS ISSUES IN AUTOMATION}

Automation of nuclear power plants will move human operators to a high level of supervisory control. Prior research (Spelt, 1993) shows that nuclear power plant control room design, especially those associated with advanced reactor concepts, are exhibiting a clear trend away from the traditional hands-on operator to one whose role is passively to monitor automated and inherently safe processes and occasionally issue permissives at preestablished hold points. The introduction of computers into the control room radically alters the work environments and the cognitive demands on the operator. While these changes tend to reduce physical workload, especially in terms of continuous manual control, mental activities may increase as new emphasis is placed on monitoring process variables and automated functions and compensating for system failures.

Questions concerning automation were part of the structured interview. At this preliminary level of this study, however, only a limited amount of facility-specific information was available. Contact with facilities currently using advanced controls is planned for further exploration of automation issues.

As shown in previous research, humans are poor monitors for low frequency events. Long periods of boredom with the associated decrease in vigilance and the lack of interaction with the control system may slowly remove the operator as an active element of the system. Such a decrease in familiarity with the state of the system has been called poor "out-of-the-loop" familiarity. Human factors experts believe that operators may be slower to detect abnormal disturbances and require a longer response time if they are not an integral part of the control loop.

Poor out-of-the-loop familiarity generally results from attempting to automate everything that is technically and economically feasible, leaving the remainder forming the nucleus of the operator's job. The problem with this approach is that it does not consider the viability of the operator's job description in light of human performance research.

Experience within the airline industry also supports these automation issues. The airlines' increasing use of glass cockpits (with their digitized information displays and alarms) and fly-by-computer control systems has resulted in experience indicating that automation must be sensitive to the strengths and limitations of human operators. Without such attention, it is likely that there will be significant control problems. This negative experience, however, has fostered the adoption of a human-centered automation perspective. This perspective keeps the operator at the center of the operation, where automation becomes an extension of the operator's will and intentions rather than a replacement for human activity. This operator-centered approach to automation is part of the ANS design philosophy.

\section{RESULTS}

Preliminary results support the role of the ANS RO as a high-level system supervisor. The traditional RO role of analog system monitoring and supervision will be considerably improved by the use of digital technology. This role improvement, which includes the use of system interactive procedures, digital measurement and logging, and implementation of lockouts and tagouts, will make the RO's actions more effective. In general, the ANS RO's base responsibilities will remain similar to those at other DOE research reactors. This position may still require significant manual interaction with the system in order to facilitate testing and calibration; moreover, at this time, such activities seem to be necessary and desirable to ensure the RO's systems awareness.

The ANS RO will ensure the appropriateness and thoroughness of automated safety functions. Ensuring safe and efficient operation (in terms of neutron production) and maintaining the availability of the reactor and the neutrons for research may be the primary goals of the RO. Success in these areas will comply with technical specifications and investment protection concerns. The ANS RO will also communicate with 
many other personnel when coordinating special processes, such as cryogenics and detritiation.

The specific roles of the ANS RO, as compiled within this study, are as follows:

$\begin{array}{ll}- & \text { supervisory controller, } \\ \circ & \text { procedure follower, } \\ 0 & \text { system configuration manager, } \\ 0 & \text { plant activities coordinator, } \\ 0 & \text { diagnostician and problem-solver, } \\ 0 & \text { testing and calibration technician, } \\ - & \text { facility decontamination technician, } \\ 0 & \text { safety technician, and } \\ - & \text { trained (i.e., certified) operator. }\end{array}$

There are three other conclusions that may be drawn from this study. First, the relationship between experimenters and the ANS ROs requires the existence of an experiment coordinator. Such a person would function as a liaison between experimenters and the operations and maintenance staff of the ANS. Currently, such communications tend to be informal at HFIR. Second, there is a consensus that the maintenance activities need to be integrated into the RO's role. The HFIR ROs have considerable maintenance responsibilities, which tend to enrich and enlarge their jobs. Furthermore, a closer tie between maintenance and operations should enhance efficiency. Third, because of the distinct and complex activities associated with cryogenics and detritiation, ROs serving in an involved supporting role will likely not be able to efficiently provide detailed assistance in these areas. Therefore, it was confirmed that special process operators both for cryogenics and for detritiation be established. A rethinking of the originally proposed auxiliary operator position was suggested.

These results are an early indication of the value of HFE activities in a major design program. As the program moves toward detailed task analyses, additional insights are expected.

\section{SUMMARY, CONCLUSIONS, AND FUTURE DIRECTIONS}

The role of the $R O$ is being studied in support of the HFE activities that are integral to the design of ANS. A structured, open-ended questionnaire was developed and administered to personnel with significant reactor experience at HFIR and engineers involved with ANS systems design.

Preliminary results indicate that the ANS RO will be a high-level system supervisor with considerable monitoring, verification, and communication responsibilities. The relatively high level of control automation in the ANS design will result in a reshaping of the RO's traditional safety and investment protection roles. In addition, the need for one or more complementary personnel was substantiated.

Near-term human factors efforts beyond this fiscal year will focus on the completion of task analysis activities, development of suggestion/justifications for levels of automation selection, completion of role analyses for other operator positions, and contribution to the ANS site staffing study. As the design of ANS evolves, plant system designers will identify operations tasks in a systematic manner, providing more definitive data for the HFE team. This information will aid in implementing the efforts described in the HFEPP.

\section{ACKNOWLEDGMENTS}

Research sponsored by the Office of Energy Research, U.S. Department of Energy, under contract DE-AC05-840R21400 with Martin Marietta Energy Systems, Inc.

\section{REFERENCES}

Houser, M. M. 1993. "Advanced Neutron Source Operating Philosophy," pp. 131137 in Proceedings of the American Nuclear Society Topical Meeting on Nuclear Plant Instrumentation, Control, and ManMachine Interface Technologies, Oak Ridge, Tennessee.

U.S. Nuclear Regulatory Commission. 1981. "Human Factors Engineering," Chapter 18 in Standard Review Plan for the Review of Safety Analysis Reports for Nuclear Power Plants, NUREG-0800, U.S. Nuclear Regulatory Commission, Washington, D.C.

\section{Schryver, J. C. 1992. Human Factors Engineering} Program Plan (for the Advanced Neutron Source), ORNL/ANS/INT-35/S5, Martin Marietta Energy Systems, Inc., Oak Ridge National Laboratory.

Spelt, P.F. 1993. "Role of the Operator in Nuclear Power Plants as Determined from a Survey of the North American Nuclear Community, " pp. 120127 in Proceedings of the American Nuclear Society Topical Meeting on Nuclear Plant Instrumentation, Control, and Man-Machine Interface Technologies, Oak Ridge, Tennessee. 


\section{DISCLAIMER}

This report was prepared as an account of work sponsored by an agency of the United States Government. Neither the United States Government nor any agency thereof, nor any of their employees, makes any warranty, express or implied, or assumes any legal liability or responsibility for the accuracy, completeness, or usefulness of any information, apparatus, product, or process disclosed, or represents that its use would not infringe privately owned rights. Reference herein to any specific commercial product, process, or service by trade name, trademark, manufacturer, or otherwise does not necessarily constitute or imply its endorsement, recommendation, or favoring by the United States Government or any agency thereof. The views and opinions of authors expressed herein do not necessarily state or reflect those of the United States Government or any agency thereof. 